\title{
US agency says Zika virus causes microcephaly
}

\author{
Owen Dyer
}

Montreal

Zika virus is the cause of a surge in birth defects across Latin America and the Caribbean, the US Centers for Disease Control (CDC) announced on 13 April, linking Zika infection during pregnancy not only to microcephaly but also to congenital blindness, stillbirth, and other fetal abnormalities.

The announcement was timed to coincide with the online publication in the New England Journal of Medicine of the conclusions of CDC experts who reviewed the evidence on Zika's pathology. ${ }^{1}$

“This study marks a turning point in the Zika outbreak," CDC's director, Tom Frieden, told reporters on a conference call. "There is no longer any doubt that Zika causes microcephaly. We believe the microcephaly is likely to be part of a range of birth defects."

He added, "Never before in history has there been a situation where a bite from a mosquito can result in a devastating malformation."

With causality established by the agency, Frieden said that CDC would now launch additional studies "to determine whether children who have microcephaly born to mothers infected by the Zika virus is the tip of the iceberg of what we could see in damaging effects on the brain and other developmental problems."

Sonja Rasmussen, the lead author of the CDC's review, said that scientists saw a consistent pattern of defects in infants exposed to the virus in utero and had found virus in brain tissue from deceased infants with microcephaly. But "many questions remain," she cautioned, including the proportion of infections during pregnancy that result in birth defects and the variation in risk from first to third trimester.

Peter Doshi, associate editor of The BMJ and a member of the faculty at the University of Maryland School of Pharmacy, recently wrote about the evidence needed to prove a causative link between microcephaly and Zika. ${ }^{2} \mathrm{He}$ said, "The CDC may well be correct in its determination, but it has jumped the gun. Both CDC and WHO [the World Health Organization] had previously indicated they would wait until early summer, pending evidence from Colombia, including two case-control studies CDC is conducting. I am concerned that CDC's new announcement may prematurely close off continued scientific discussion of the question, including the role of co-factors. I also wonder: will WHO still carry out its own independent analysis of the causality question, as it had said it would, or will it defer to CDC?"

The review was published at the same time as two case series on babies born with microcephaly, one in The BMJ and one in a letter in the New England Journal of Medicine. ${ }^{3}$ The series reported the cases of 23 infants with microcephaly associated with Zika virus seen in the Pernambuco state of Brazil. One infant was reported in both series.

The $B M J$ paper reported detailed findings from computed tomography and magnetic resonance imaging of the infants' brains. $^{3}$ These showed that most infants had brain damage that was "extremely severe, indicating a poor prognosis for neurological function," said the doctors.

All babies who underwent computed tomography showed signs of brain calcification. Other common findings included malformations of cortical development, decreased brain volume, and ventriculomegaly. The doctors also observed underdevelopment of the cerebellum.

Magnetic resonance imaging showed that most babies had an enlarged cisterna magna, probably resulting from reduced brain volume. There was also delayed myelination and abnormalities of the corpus callosum.

The case series published as a letter in the New England Journal of Medicine was based on head computed tomography of 23 babies and also showed a range of brain abnormalities, including widespread calcification, hypogyration of the cerebral cortex, and cerebellar hypoplasia. Ventriculomegaly was found in all the infants and was rated as severe in the majority (53\%) and involving only the lateral ventricles in $43 \%$.

\section{thebmj.com Feature Convicting Zika doi:10.1136/bmj.i1847}

1. Rasmussen SA, Jamieson DJ, Honein MA, Petersen LR. Zika Virus and Birth Defects Reviewing the Evidence for Causality. N Engl J Med 2016;13. doi:10.1056/ NEJMsr1604338. pmid:27074377.

2 Doshi P. Convicting Zika. BMJ 2016;353:11847. doi:10.1136/bmj.i1847 pmid:27056643.

3 de Fatima Vasco Aragao M, van der Linden V, Brainer-Lima AM, et al. Features and neuroimaging (CT and MRI) findings in presumed Zika virus related congenital infection and microcephaly: retrospective case series study. BMJ2016;353:11901doi:10.1136/bmj. i1901.

4 Hazin AN, Poretti A, Cruz DD, et al. Microcephaly Epidemic Research Group. Computed tomographic findings in microcephaly associated with Zika virus. N Engl J Med 2016. doi: 10.1056/NEJMc1603617 pmid:27050112.

Published by the BMJ Publishing Group Limited. For permission to use (where not already granted under a licence) please go to http://group.bmj.com/group/rights-licensing/ permissions 